\title{
Electrocardiographic Markers of Fibrosis in Cardiomyopathy: A Beginning of a Long Journey
}

\author{
M. Juhani Junttila
}

Research Unit of Internal Medicine, Medical Research Center, University Hospital of Oulu, and University of Oulu, Oulu, Finland

Identifying asymptomatic patients with myocardial disease with feasible clinical tools in order to reduce cardiac events is of great importance. Accumulation of myocardial fibrosis is a common feature in almost all cardiac diseases. Eventually, excessive amounts of fibrosis will lead to heart failure; however, during a relatively long latency phase, fibrosis already results in a risk for lifethreatening arrhythmias and sudden cardiac death (SCD). Additionally, myocardial reformation as a consequence of fibrosis is very variable. Environmental and/or genetic factors in different individuals cause loss of systolic functional properties in one and launch refractory hypertrophy in others which results in even more diversity in individual risk assessment. Even when systolic function remains intact, mainly due to refractory hypertrophy, accumulation of fibrosis causes areas of slow conduction in the ventricular wall which is a traditional requirement for arrhythmogenity [1]. Therefore, identifying myocardial fibrosis with feasible methods is a very interesting research topic. Currently, the most credible examination on detecting myocardial fibrosis is cardiac magnetic resonance imaging (cMRI). Occurrence of late gadolinium enhancement (LGE) in cMRI, which accurately shows focal fibrotic lesions, has been associated with increased

karger@karger.com

(c) 2020 S. Karger AG, Basel

www.karger.com/crd

Karger! risk for ventricular arrhythmias in both dilated and hypertrophic cardiomyopathy (HCM) [2,3]. Furthermore, cMRI T1 relaxation time seems promising for identifying scattered interstitial fibrosis, which is undetected in LGE imaging, but can potentially cause similar risk for arrhythmias [4]. The only problem is that at the moment, cMRI cannot be considered as a screening tool due to availability and pricing issues. Further prescreening is needed in choosing the right patients for cMRI.

One of the most common, or at least most recognized, causes for nonischemic SCD is HCM which has been speculated to be the most common cause for SCD among young athletes. The current European Society of Cardiology guidelines for HCM focus on prior symptoms, echocardiographic parameters, and hemodynamical reactions during exercise. The only ECG-related risk parameter is occurrence of nonsustained ventricular tachycardia. Until now, no ECG morphology or cMRI fibrosis parameters are included [5].

Electrocardiogram has been a cheap and widely accessible examination worldwide for decades. The applicability of ECG in the assessment of risk for adverse events, in another setting than emergency care, has been under major research efforts during the last decade. One interesting 
new comer in this field has been the inferolateral early repolarization (ER) pattern, which has been considered as a normal variant for decades, but has recently been associated with increased risk for cardiac death and SCD in the general population and in many cardiac diseases, including HCM [6-8]. At the moment, there is no consensus on whether the slur or notch in the terminal part of the QRS complex is caused by ER of delayed depolarization.

In the current issue of Cardiology, Azevedo et al. [9] present the association of myocardial fibrosis, hypertrophy, and inferolateral ER pattern among HCM patients.
They show that inferolateral ER is associated with a higher left ventricular mass in cMRI, but not with LGE. Therefore, it would seem that ER might not be a good marker for fibrosis in HCM patients. However, the study did not seem to answer whether relaxation time derived from $\mathrm{T} 1$ mapping was associated with ER which would be also interesting due to the association with scattered interstitial fibrosis. In this respect, the job is not done yet. The authors do bring forth a major concept which needs to be explored in all myocardial diseases, including acquired myocardial diseases.

\section{References}

1 de Jong S, van Veen TA, van Rijen HV, de Bakker JM. Fibrosis and cardiac arrhythmias. J Cardiovasc Pharmacol. 2011 Jun;57(6):6308.

2 Chimura M, Kiuchi K, Okajima K, Shimane A, Sawada T, Onishi T, et al. Distribution of Ventricular Fibrosis Associated With LifeThreatening Ventricular Tachyarrhythmias in Patients With Nonischemic Dilated Cardiomyopathy. J Cardiovasc Electrophysiol. 2015 Nov;26(11):1239-46.

3 Chan RH, Maron BJ, Olivotto I, Pencina MJ, Assenza GE, Haas T, et al. Prognostic value of quantitative contrast-enhanced cardiovascular magnetic resonance for the evaluation of sudden death risk in patients with hypertrophic cardiomyopathy. Circulation. 2014 Aug; 130(6):484-95.
4 Maragiannis D, Alvarez PA, Ghosn MG, Chin $\mathrm{K}$, Hinojosa JJ, Buergler JM, et al. Left ventricular function in patients with hypertrophic cardiomyopathy and its relation to myocardial fibrosis and exercise tolerance. Int J Cardiovasc Imaging. 2018 Jan;34(1):121-9.

5 Authors/Task Force members. Elliott PM, Anastasakis A, Borger MA, Borggrefe M, Cecchi F, Charron P, Hagege AA, Lafont A, Limongelli G, Mahrholdt H, McKenna WJ, Mogensen J, Nihoyannopoulos P, Nistri S, Pieper PG, Pieske B, Rapezzi C, Rutten FH, Tillmanns C, Watkins H. 2014 ESC Guidelines on diagnosis and management of hypertrophic cardiomyopathy: the Task Force for the Diagnosis and Management of Hypertrophic Cardiomyopathy of the European Society of Cardiology (ESC). Eur Heart J. 2014;35:2733-79.
6 Tikkanen JT, Anttonen O, Junttila MJ, Aro AL, Kerola T, Rissanen HA, et al. Long-term outcome associated with early repolarization on electrocardiography. N Engl J Med. 2009 Dec;361(26):2529-37.

7 Tikkanen JT, Wichmann V, Junttila MJ, Rainio M, Hookana E, Lappi OP, et al. Association of early repolarization and sudden cardiac death during an acute coronary event. Circ Arrhythm Electrophysiol. 2012 Aug; 5(4):714-8.

8 Tsuda T, Hayashi K, Konno T, Sakata K, Fujita T, Hodatsu A, et al. J Waves for Predicting Cardiac Events in Hypertrophic Cardiomyopathy. JACC Clin Electrophysiol. 2017 Oct; 3(10):1136-42.

9 Azevedo PM, Guerreiro C, Ladeiras-Lopes R, Ferreira N, Faria R, Barbosa R, et al. Early Repolarization Pattern and Left Ventricular Mass in Hypertrophic Cardiomyopathy. Cardiology. 2020; Epub ahead of print. 